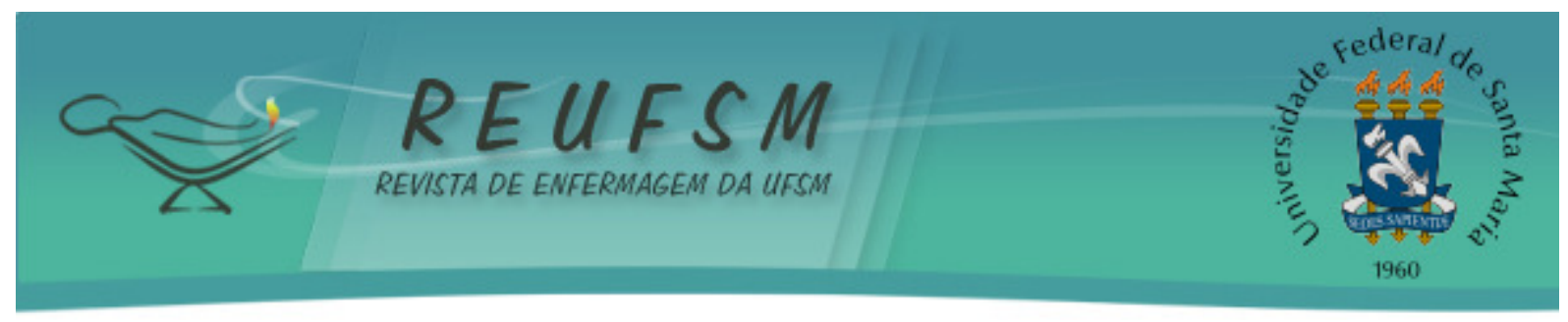

ARTIGO ORIGINAL

\title{
EDUCAÇÃO E SAÚDE NO COTIDIANO DE ENFERMEIRAS DA ATENÇÃO PRIMÁRIA
}

\author{
EDUCATION AND HEALTH IN THE DAILY PRACTICE OF PRIMARY CARE NURSES \\ EDUCACIÓN Y SALUD EN EL COTIDIANO DE ENFERMERAS DE LA ATENCIÓN PRIMARIA
}

Geyse Aline Rodrigues Dias ${ }^{1}$

Márcia Maria Bragança Lopes ${ }^{2}$

Doi: $10.5902 / 217976927846$

RESUMO: Objetivo: desvelar o cotidiano da prática educativa de enfermeiras na Atenção Primária. Método: pesquisa exploratória, com abordagem qualitativa, realizada com quatro enfermeiras de uma Unidade Estratégia Saúde da Família, localizada no município de BelémPará-Brasil. Os dados foram coletados por meio de entrevista semiestruturada e analisados com auxílio da técnica da Teoria Fundamentada nos Dados. Resultados: foram organizados em duas categorias: A dimensão das ações educativas das enfermeiras na Atenção Primária e A práxis das ações educativas desenvolvidas pelas enfermeiras na Atenção Primária, que explicitaram o predomínio do modelo tradicional de educação em saúde e a carência de conhecimento científico aplicado nas ações educativas. Considerações Finais: acredita-se que a educação em saúde ainda seja um desafio, mas que deve ser pensada como um processo a ser galgado pelos profissionais dos serviços de saúde, quando no desenvolvimento de práticas educativas voltadas para a realidade da população.

Descritores: Atenção primária à saúde; Educação em saúde; Enfermagem.

ABSTRACT: Aim: to unveil the daily educational practice of nurses in primary care. Method: exploratory research with qualitative approach, performed with four nurses from a family health Strategy Unit, located in Belém-Pará-Brazil. The data were collected through semi-structured interview and analyzed using the technique of Grounded Theory. Results: Were organized into two categories: The size of educational actions of nurses in primary care and the praxis of educational actions developed by nurses in the primary care, which demonstrated the predominance of the traditional model for information on health education and the lack of scientific knowledge applied in educational actions. Conclusion: it is believed that this health education is still a challenge, but that should be thought of as a process to be achieved by the professionals from health services, when developing educational practices focused on the reality of the population.

Descriptors: Primary health care; Health education; Nursing.

RESUMEN: Objetivo: desvelar el cotidiano de las prácticas educativas de enfermeras en la atención primaria. Método: investigación de carácter exploratorio, cualitativo, realizada con 4 enfermeras de una Unidad de Salud de la Familia, en Belém, Pará, Brasil. Los datos fueron colectados a través de entrevista semiestructurada y analizados mediante la técnica de la Teoría Fundamentada en los Datos. Resultados: fueron organizados en dos

\footnotetext{
${ }^{1}$ Enfermeira. Mestranda do Programa de Pós-graduação em Enfermagem da Universidade Federal do Pará (UFPA). Membro do grupo de Estudos em Educação, formação e gestão para práxis do cuidado de enfermagem/UFPA. Belém, PA, Brasil. E-mail: geysealine@hotmail.com

${ }^{2}$ Enfermeira. Doutora em Enfermagem pela Universidade Federal de Santa Catarina. Docente da Faculdade de Enfermagem e do Programa de Pós-graduação em Enfermagem da UFPA. Líder do Grupo de Estudos em Educação, formação e gestão para práxis do cuidado de enfermagem/UFPA. Belém, PA, Brasil. E-mail: mmbl@ufpa.br
} 


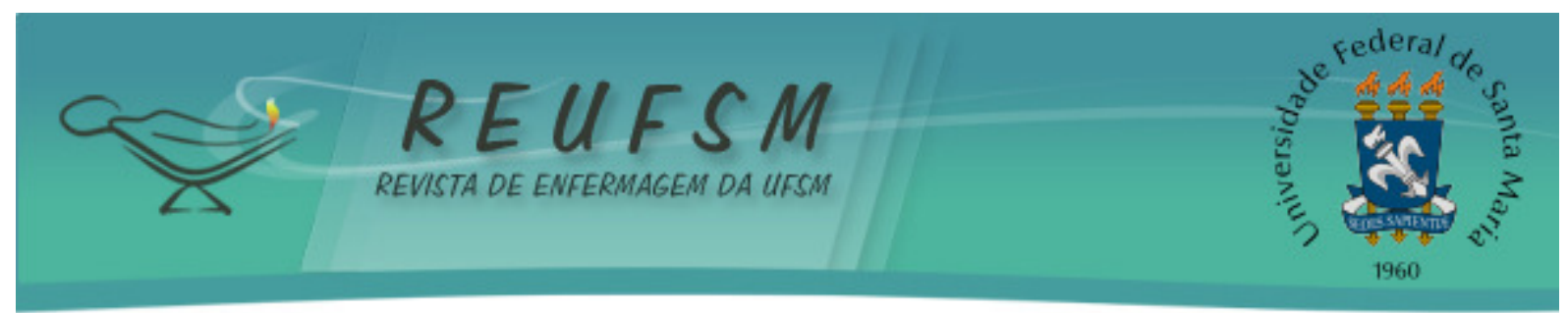

categorías: la dimensión de las acciones educativas y la praxis de las acciones educativas desarrolladas por las enfermeras en la atención primaria, que demuestran el predominio del modelo tradicional sobre educación para la salud y la falta de conocimientos científicos aplicados en acciones educativas. Conclusión: la educación en salud es un desafío que debe ser pensado como un proceso para ser alcanzado por los profesionales en el desarrollo de las prácticas educativas direccionadas a la realidad de la población.

Descriptores: Atención primaria de salud; Educación en salud; Enfermería.

\section{INTRODUÇÃO}

A proposta de educação em saúde não é recente, já que houve sempre uma intenção de se estruturar ações educativas visando ampliar informações da população sobre as doenças, ressaltando diversas recomendações sobre condutas certas ou erradas relacionadas à situação das doenças e à sua prevenção. ${ }^{1}$

O conceito de educação em saúde está ligado à promoção à saúde, que aborda processos que envolvem a participação de toda a população, independente do seu estado de saúde. Isto se ancora no conceito de saúde, considerado um estado positivo e dinâmico de busca pelo bem-estar físico, mental, pessoal e social. ${ }^{2}$

$\mathrm{Na}$ educação em saúde, como fonte de promoção da saúde e prevenção de doenças e agravos, o cuidado vai além do processo curativo, com intervenção social, ambiental e educacional. Essas abordagens auxiliam os sujeitos a buscarem autonomia e exercitar sua cidadania. ${ }^{3}$ Como forma de atuação do profissional enfermeiro, coloca-se como uma das estratégias para promover saúde. ${ }^{4}$ Entretanto, as ações educativas ainda são pouco utilizadas nessa perspectiva, visto que as concepções, objetivos e metodologias empregadas não favorecem mudanças à saúde. ${ }^{5}$

Em um contexto mais recente observa-se que a prática educativa da enfermeira necessita ir além de ações que "privilegiam o repasse de informações e normas de maneira vertical às famílias e grupos". ${ }^{5: 3}$ Há a necessidade de respeitar o homem como ser biopsicossocial para assim atingir mais profundamente a sua participação dentro do processo educativo.

Como instrumento essencial dessa prática, na busca das transformações entendidas pelos profissionais e comunidade como necessárias, considera-se a ação educativa aliada ao diálogo, à participação, e à ação-reflexão-ação, como estratégia para minimizar os efeitos deletérios das situações sociocultural e estrutural em que se encontram os usuários. Isto significa que, como prática dialogada e participativa, a prática educativa tem como objetivo a transformação da realidade de saúde dos sujeitos e grupos sociais assistidos. ${ }^{6}$

A prática de atenção primária à saúde, conceituada como "um conjunto de ações de saúde no âmbito individual e coletivo que abrangem a promoção e proteção da saúde, prevenção de agravos, diagnóstico, tratamento, reabilitação e manutenção da saúde" 7:12, presume o cuidado integral. ${ }^{8}$ Considerando a concepção de integralidade, as ações de educação em saúde, desenvolvidas nas práticas educativas, são estratégias articuladas entre a concepção da realidade do contexto de saúde e a busca de possibilidades de atitudes geradoras de mudanças a partir de cada profissional de saúde, do trabalho em equipe e dos diversos serviços que buscam uma transformação no quadro da saúde da população. ${ }^{2}$ Diante de sua importância para o trabalho desenvolvido na atenção primária, particularmente na Estratégia Saúde da Família (ESF), e considerando que a prática educativa é rotineiramente permeada por problemas que indiscutivelmente dificultam o alcance de seu objetivo ideal, acredita-se que conhecer a realidade da comunidade, objeto desta prática, é essencial para o desenvolvimento de novas ações na busca incessante do objetivo de transformação.

Para tanto, este estudo foi conduzido pela seguinte questão norteadora: como vêm sendo desenvolvidas as ações educativas por um grupo de enfermeiras na Atenção 


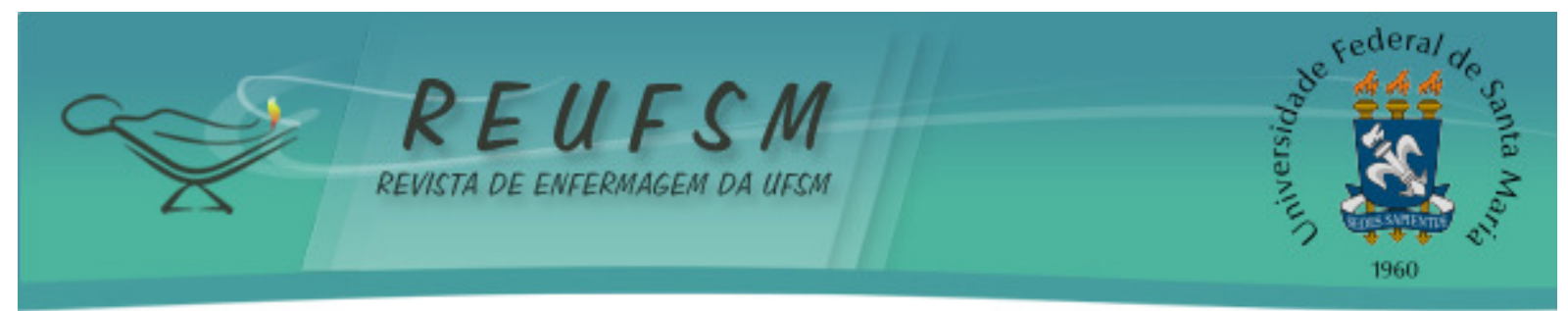

Primária? Baseado na perspectiva de conhecer como este grupo de enfermeiras desenvolve ações educativas em seu cotidiano, este estudo teve como objetivo desvelar o cotidiano da prática educativa de enfermeiras na Atenção Primária.

\section{MÉTODO}

Trata-se de um estudo exploratório com abordagem qualitativa, resultado do projeto de pesquisa intitulado "Realidade Amazônica: razões e dificuldades para o desenvolvimento de ações educativas na prática de enfermeiras na atenção básica".

A pesquisa foi realizada em uma Unidade Estratégia Saúde da Família (ESF), localizada em um bairro da periferia do município de Belém-Pará-Brasil, no Distrito Administrativo do Guamá, denominado Distrito de Saúde D’Água.

Os critérios para inclusão dos sujeitos no estudo foram: ser enfermeiro e estar desenvolvendo suas atividades na instituição. Foram excluídos enfermeiros que se encontravam de férias ou licença saúde no período da realização das entrevistas e os que não aceitaram participar do estudo.

Os sujeitos deste estudo foram quatro enfermeiras, o total de profissionais lotadas na unidade, selecionadas de acordo com os critérios acima descritos e que concordaram em assinar o Termo de Consentimento Livre e Esclarecido (TCLE). A coleta de dados foi realizada por meio de entrevistas individuais, semiestruturadas e aconteceu na própria unidade ESF, conforme a disponibilidade de horários das enfermeiras e após autorização para a gravação, por parte das entrevistadas, bem como pela garantia, por parte do entrevistador, do sigilo e da confidencialidade das informações proporcionadas. Desse modo, os sujeitos foram representados pelos codinomes de Rosa, Violeta, Lírio e Orquídea.

O protocolo de entrevista foi composto de seis itens, que exploraram: como as profissionais avaliam as suas ações educativas; como realizam sua prática; quais dificuldades são encontradas; como enfrentam as dificuldades e; que facilidades são encontradas no desenvolvimento das suas ações educativas na atenção básica de saúde. As explanações foram gravadas em arquivo digital e o tempo variou de quinze a vinte e cinco minutos de duração.

A análise foi realizada através da Teoria Fundamentada nos Dados. ${ }^{9}$ Essa estratégia propõe o ordenamento conceitual, que é a organização de dados em um esquema classificatório, por categoria ou por classificação, segundo as suas propriedades e suas dimensões. ${ }^{9}$

No processo de codificação dos dados, as entrevistas foram transcritas e examinadas, recortando as unidades de análises e feita a codificação substantiva dos dados, através das codificações aberta e axial.

Na primeira fase, codificação aberta, os dados foram examinados, comparados e feitos os questionamentos sobre o fenômeno que procede, a fim de se extrair as ideias principais gerando códigos.

\begin{tabular}{|c|c|c|}
\hline TRANSCRIÇÃO LITERAL & UNIDADE DE ANÁLISE & CÓDIGO \\
\hline $\begin{array}{l}\text { Eu faço geralmente de quinze em } \\
\text { quinze dias, em termo de tempo, } \\
\text { toda quarta-feira eu faço uma } \\
\text { ação educativa. Em termo de } \\
\text { técnica eu uso a fala, muito a } \\
\text { fala, porque aqui é muito pobre } \\
\text { em termos de materiais técnicos. } \\
\text { (LíRIO) }\end{array}$ & $\begin{array}{l}\text { Eu faço geralmente de quinze em } \\
\text { quinze dias, em termo de tempo. } \\
\text { (LíRIO) } \\
\text { Em termo de técnica eu uso a } \\
\text { fala, muito a fala. (LíRIO) }\end{array}$ & $\begin{array}{l}\text { - Descrevendo com que } \\
\text { periodicidade } \\
\text { realizadas suas ações } \\
\text { educativas na prática da } \\
\text { atenção básica. } \\
\text { - Explicando de que forma } \\
\text { realiza suas ações } \\
\text { educativas na prática da } \\
\text { atenção básica. }\end{array}$ \\
\hline
\end{tabular}

Quadro 1 - Exemplo de um processo de codificação aberta. 


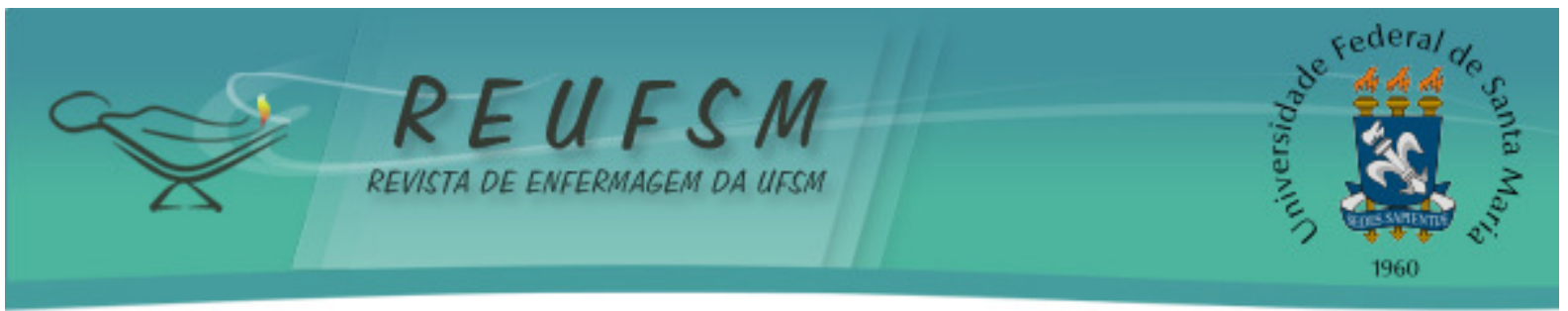

Na segunda fase, codificação axial, os códigos construídos na fase anterior foram relacionados e agrupados de tal forma a permitir conexões que identificassem subcategorias, mais abstratas e abrangentes para o estudo. Nessa fase as subcategorias foram integradas e definidas de tal modo que permitissem descobrir a categoria central.

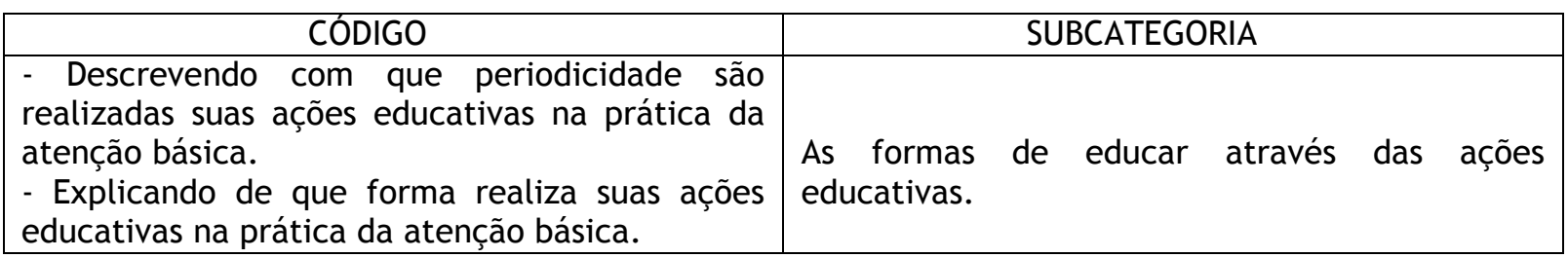

Quadro 2 - Exemplo de um processo de codificação axial.

Após realizar a análise da codificação axial, reduziu-se o número de subcategorias e de categorias até chegar ao modelo mais aproximado de relação entre a categoria e as subcategorias.

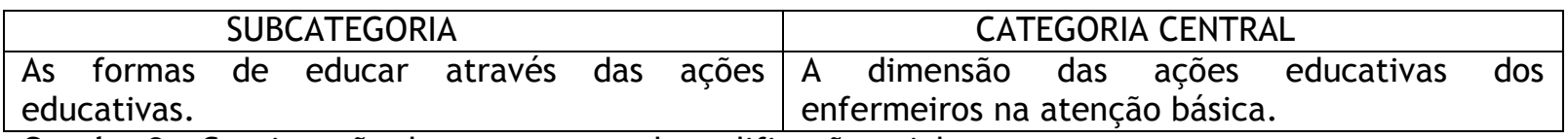

Quadro 3 - Continuação de um processo de codificação axial.

No estudo emergiram no total duas categorias de análise, quais sejam: "A dimensão das ações educativas das enfermeiras na atenção primária" e "A práxis das ações educativas desenvolvidas pelas enfermeiras na atenção primária"; e seis subcategorias, quais sejam: "Importância e finalidade das ações educativas"; "As formas de educar através das ações educativas"; "Conhecimento científico aplicado nas ações educativas"; "Dificuldades para o desenvolvimento das ações educativas na prática da atenção primária"; "Enfrentamento das dificuldades encontradas no desenvolvimento das ações educativas na prática da atenção primária"; "Facilidades no desenvolvimento das ações educativas na prática da atenção primária”.

0 projeto de pesquisa foi aprovado pelo Comitê de Ética em Pesquisa com Seres Humanos do Instituto de Ciências da Saúde da Universidade Federal do Pará (ICS-UFPA), com parecer $n^{\circ} 030 / 11$ e pela Comissão para Análise de Projetos de Pesquisa da Secretaria Municipal de Saúde de Belém-Pará (SESMA).

\section{RESULTADOS E DISCUSSÃO}

Os dados obtidos resultaram em duas categorias analíticas, primeiramente serão apresentadas duas subcategorias relativas à categoria "A dimensão das ações educativas das enfermeiras na Atenção Primária" e em seguida quatro subcategorias relativas à categoria "A práxis das ações educativas desenvolvidas pelas enfermeiras na Atenção Primária".

\section{Importância e finalidade das ações educativas}

Entende-se por ações educativas as práticas de ensino-aprendizagem desenvolvidas juntamente à população com a finalidade de debater e promover a tomada de decisão em relação a atitudes e práticas de saúde, através da reflexão crítica de ambos os atores. ${ }^{10}$

Nessas falas as enfermeiras avaliaram de forma positiva as ações educativas desenvolvidas por elas no seu cotidiano: 


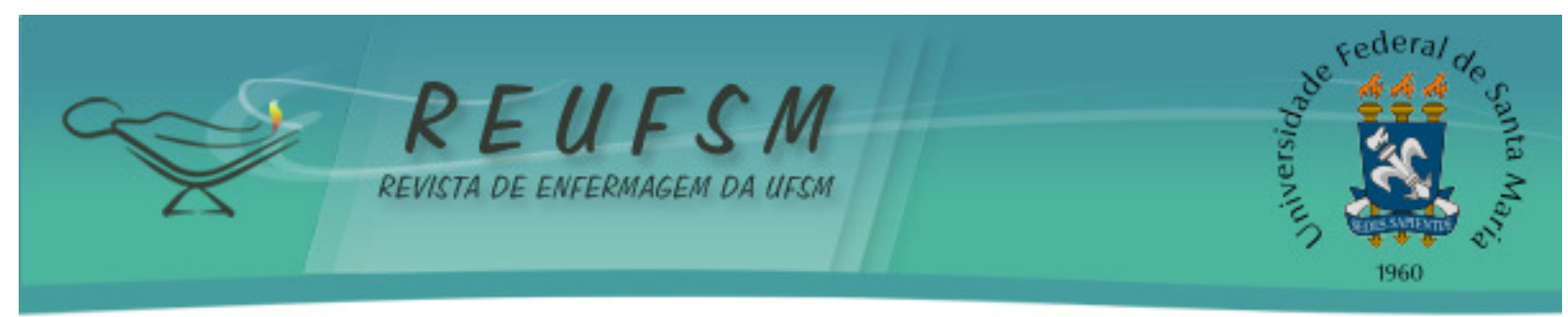

Eu avalio como uma forma positiva do meu trabalho, porque as nossas ações educativas são voltadas para o usuário, para a comunidade. (ROSA)

Eu avalio de forma positiva, porque assim, dependendo dos recursos a gente tenta fazer da melhor forma possível. (ORQUÍDEA)

Em relação as dimensões das ações educativas as profissionais avaliam positivamente seu trabalho, considerando que todo ele é direcionado para o usuário e para a comunidade. Observou-se ainda que os recursos disponíveis para realização das ações educativas são importantes para o bom desenvolvimento do trabalho educativo, já que dão suporte para o melhor desempenho da profissional.

“A educação em saúde como um processo, está sempre em construção. Tal construção de conhecimento deve ocorrer na relação dialogada entre profissional-usuário buscando nas vivências, o ponto de partida da prática educativa". 11:413

Vale ressaltar a importância dos recursos didáticos no desenvolvimento de ações educativas como estratégia de consolidação de conhecimentos. Entretanto, sua seleção deve estar condicionada ao grau de compreensão do grupo a ser trabalhado, visando o alcance dos objetivos daquelas ações educativas.

Por outro lado se evidenciam, também, análises críticas a respeito das ações educativas desenvolvidas pelas enfermeiras:

A minha avaliação é a seguinte: tem o ideal e o real. $O$ ideal seria uma atenção voltada para o paciente com a intenção de prevenir que o indivíduo venha a adoecer. É o objetivo. (VIOLETA)

Analisando a fala acima, identificou-se que as enfermeiras conhecem a finalidade, os objetivos e a importância das ações educativas, reconhecendo, entretanto, que em função da realidade vivenciada pela comunidade assistida, há dificuldade em alcançar os objetivos a que se propõem ao realizar estas ações.

A educação em saúde é uma tarefa que depende de profissionais com habilidades e competências para orientar as pessoas a promover a saúde, evitar riscos à saúde, restaurar a saúde e prevenir doenças. ${ }^{10}$

Nesse contexto se torna responsabilidade dos profissionais, atentar e praticar a educação em saúde como processo educativo de construção de conhecimento, contribuindo para aumentar a autonomia das pessoas no seu cuidado e no debate com os profissionais para alcançar uma atenção de saúde de acordo com suas necessidades.

\section{As formas de educar através das ações educativas}

Quanto às formas de educar em saúde, predominaram menções às orientações e informações individuais oferecidas em consultório, e atividades educativas coletivas que são desenvolvidas através de palestras, reuniões e passeios com a população. No entanto, o objetivo principal da educação em saúde não é somente de informar para a saúde, mas de transformar os saberes existentes no contexto.

Através de palestras, de reuniões do Hiperdia, através de atividades, como por exemplo, passeio com os idosos. (ROSA) 


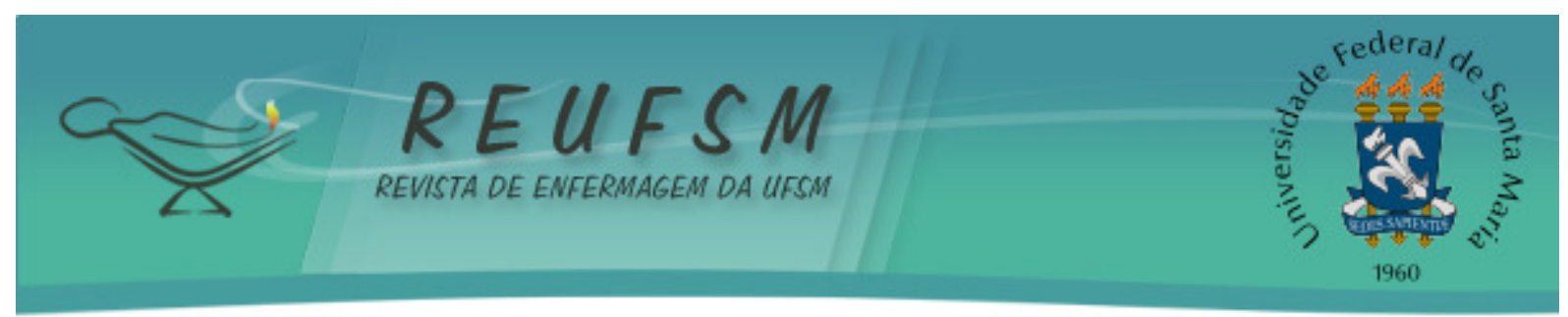

É no consultório e nas visitas domiciliares, eu vou à visita e também eu faço orientações. (VIOLETA)

Identificou-se que há o desenvolvimento de atividades educativas dentro e fora da unidade de saúde junto à comunidade, ressaltando que a ação educativa, como manifestação de cuidado em Enfermagem, pode acontecer planejadamente e formalmente, bem como de maneira informal, dialogando-se com a comunidade e durante as visitas domiciliares ${ }^{12}$. Nesse processo, os encontros individuais e/ou grupais, devem configurar espaços de participação e livre diálogo, tanto para o profissional quanto para o usuário, buscando a compreensão e o conhecimento das condições socioculturais e ambientais e as necessidades de saúde do indivíduo e comunidade, criando estratégias e possibilidades para que haja a troca de saberes e construção de conhecimento. ${ }^{13}$

Percebeu-se ainda que, mesmo timidamente, já há profissionais que utilizam as formas de educar muito além da reunião de grupos e repasse de informações à população, como observado no relato:

Eu nunca vou para comunidade como um tema definido. [...] Eu não vou à comunidade falar sobre alimentação, mas a comunidade pede para falar, então eu pergunto o que vocês sabem sobre alimentação? Primeiro eu vejo o grau do que eles [os usuários do serviço] conhecem para poder depois estar trabalhando o que eles não conhecem. (ORQUÍDEA)

As enfermeiras reconhecem a importância de se conhecer a realidade e as necessidades da comunidade, para despertar o interesse, reflexões e gerar a autonomia dos indivíduos em relação à saúde. Porém, ainda é um desafio nas perspectivas de educação em saúde despertar nos profissionais o interesse em conhecer e reconhecer as dificuldades cotidianas da população.

Nesta perspectiva, a prática educativa busca nos indivíduos o desenvolvimento da autonomia e da responsabilidade no cuidado com a saúde, por meio da compreensão da situação de saúde e não por um saber técnico-científico imposto e transmitido pelo profissional de saúde. ${ }^{14}$

Para isso, ainda é necessário superar o autoritarismo e a cultura normativa que vigora nos serviços, visando à construção e o desenvolvimento de propostas de organização da comunidade e de mudança das suas condições de vida e saúde. ${ }^{15}$

A educação em saúde como processo político pedagógico requer o desenvolvimento de um pensar crítico e reflexivo, permitindo desvelar a realidade e propor ações transformadoras que levem o indivíduo a sua autonomia e emancipação, enquanto sujeito histórico e social capaz de propor e opinar nas decisões de saúde para o cuidar de si, de sua família e da coletividade. $2: 341$

Logo, para autonomizar o usuário é necessário promover informações e utilizar estratégias que favoreçam escolhas responsáveis no seu modo de viver, proporcionando mais qualidade de vida e independência dos atos de saúde. ${ }^{16}$

Isto tem implicações sobre a realização de práticas de educação em saúde, seja do ponto de vista de sua viabilidade no cotidiano do serviço, seja no resgate do seu papel como espaço de instituição de novos modos de relação entre profissionais e usuários e de contribuição para a autonomia destes. 


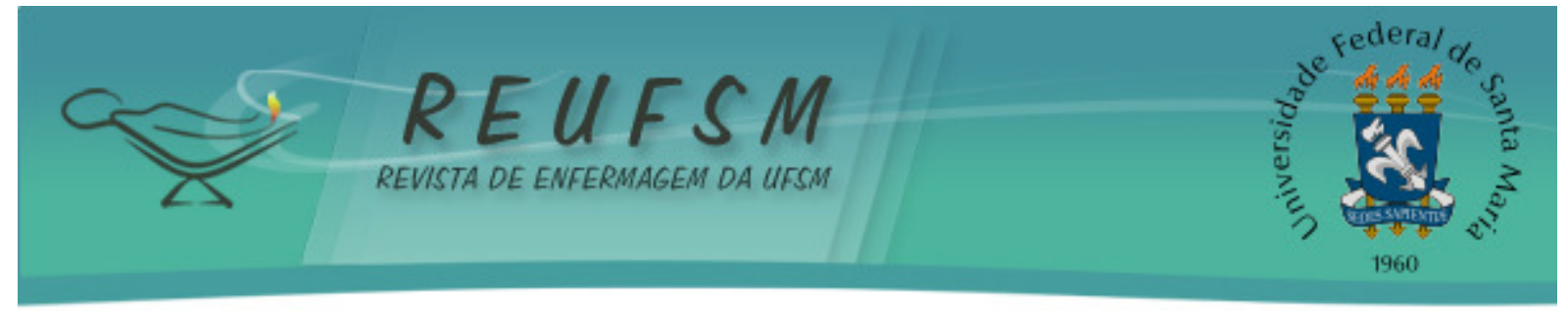

Conhecimento científico aplicado nas ações educativas

Nas falas a seguir as enfermeiras relatam que utilizam o conhecimento científico conforme a faixa etária, o grau de entendimento e do que avaliam ser necessário para população.

Eu uso dependendo do momento, é de acordo com grupo que estou trabalhando, se é um grupo de hipertensos e diabéticos vou enfocar aquele grupo, abranger aquele conhecimento do momento. (ROSA)

Eu uso do que eu sei e tento reverter até pela própria educação de cada um deles [usuários do serviço] para que seja um linguajar favorável, mas com certeza eu uso o conhecimento da minha academia. (LÍRIO)

Eu acho que uso todo o meu conhecimento científico dentro das ações. Mas em relação à linguagem da comunidade tenho que ir bem acessível, porque não tem como jogar termos técnicos de conhecimento científico, algumas coisas nós falamos, mas explicamos o que significa. (ORQUÍDEA)

Perceberam-se dificuldades em correlacionar o conhecimento científico às ações desenvolvidas. Nesse sentido, conhecer criativamente e combinar as práticas profissionais de enfermagem com a realidade dos usuários é um desafio para o enfermeiro ${ }^{17}$, mas é válido destacar a preocupação dos profissionais quanto à maneira que utilizam o seu conhecimento científico com os usuários durante as ações educativas, visto que se trata de uma forma de aproximação com a comunidade, percebendo as necessidades da mesma.

Para tanto, ainda é necessário viabilizar o debate e a construção compartilhada de estratégias de ação voltadas à melhoria das condições de saúde e vida da população ${ }^{18}$, pois o usuário como sujeito portador de um saber, tem capacidade de manter uma relação dialógica com o serviço, tornando-se crítico sobre a sua realidade e aprimorando as possibilidades de enfrentamento sobre o seu processo saúde-doença-cuidado. ${ }^{14}$

Com base nas reflexões da práxis de educação em saúde, a partir da construção do conhecimento, infere-se a necessidade de efetuar um processo educativo em saúde que abranja a comunidade, tendo como eixo norteador das ações de saúde a participação da população, com reflexão crítica de sua realidade na busca por ações transformadoras, que ressaltem o seu papel histórico e social capaz de tomar decisões sobre as suas necessidades de saúde. ${ }^{2}$

\section{Dificuldades para o desenvolvimento das ações educativas na prática da atenção primária}

Vários entraves foram destacados, tais como barreiras institucionais relacionadas às limitações de recursos materiais e de espaço físico, o desinteresse da população em participar das atividades e a violência da localidade, que sofre grande influência do tráfico de drogas.

Não tem espaço físico pra fazer uma educação em saúde. [...] $E$ tem a questão de material educativo que não tem. (VIOLETA)

o número de pessoas é muito pequeno, principalmente as mulheres, pois geralmente os horários das ações educativas são no 


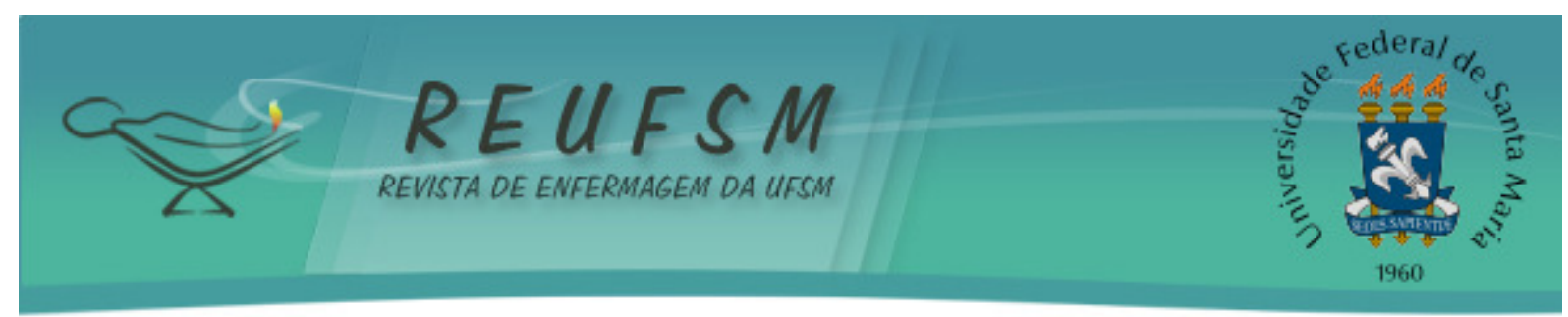

período de maior afazer doméstico, isso dificulta a ida delas no local, mas a gente vê muito desinteresse da população. (LÍRIO)

\section{[...] Eu acho que a dificuldade é a violência mesmo. (ORQUÍDEA)}

As dificuldades relacionadas às condições materiais, espaço físico e recursos foram relatadas em outros estudos como entraves importantes à realização das atividades educativas coletivas. ${ }^{19}$ Tais complicações contribuem significativamente para carência de desenvolvimento de ações educativas.

Quanto ao não comparecimento dos usuários às atividades de educação em saúde, geralmente acontece, em função do seu contexto de vida e a vulnerabilidade do local, que se trata de uma área periférica e com grande influência do tráfico de drogas.

Essa realidade também atinge o profissional que atua na ESF, pois ele encontra-se mais vulnerável pela precariedade de estratégias que o auxilie a lidar com as diversas complexidades de sua atuação em relação à comunidade que assiste, visto que são áreas de alto risco social que necessitam de uma atuação diferenciada, de uma estreita relação da equipe de saúde com a população atendida. ${ }^{20}$

Tais dificuldades influenciam de forma negativa o pleno desenvolvimento das práticas das enfermeiras, pois limitam as ações educativas e desestimulam as profissionais na sua realização. E não se tratam somente de dificuldades, mas de problemas que afetam a práxis educativa das profissionais e desmotivam de certa forma, a participação da comunidade no processo educativo.

\section{Enfrentamento das dificuldades encontradas no desenvolvimento das ações educativas na prática da atenção primária}

As dificuldades relatadas pelas enfermeiras tais como limitações de recursos, de espaço físico, o próprio desinteresse da população em participar das ações e a violência local, são entraves que atrapalham o pleno desenvolvimento das ações educativas na atenção primária e necessitam de cautela para o seu enfrentamento.

Identificou-se que as estratégias mais utilizadas no confrontamento dessa realidade, estão relacionadas a parcerias externas, com instituições de ensino por meio de programas de extensão, com os Agentes Comunitários de Saúde (ACS) e com a compra de materiais com recursos próprios. Tais estratégias amenizam a deficiência e a carência das ações educativas, mas não são suficientes para sanar as objeções que permeiam o trabalho das enfermeiras.

A gente conta com alguns alunos do PET (Programa de Educação pelo Trabalho para a Saúde) ou das próprias faculdades de enfermagem que passam por aqui fazendo estágio, isso ajuda muito. [...] quando queremos fazer uma coisa [ação educativa], reunimos os ACSs pra ver se eles podem conseguir isso ou aquilo. 0 material é insuficiente, adquiri-se assim a maioria das vezes comprando. E quando a capacitação não é aqui, faz-se nas escolas, no centro comunitário ou na igreja. (ROSA)

Nas falas identificou-se que as enfermeiras utilizam como incentivo a presença da comunidade nas ações educativas, a solicitação de exames, o desenvolvimento de dinâmicas durante as ações e a presença do profissional médico. Infere-se que o principal objetivo da população nesse contexto é suprir outras necessidades, como a de conseguir consultas e 


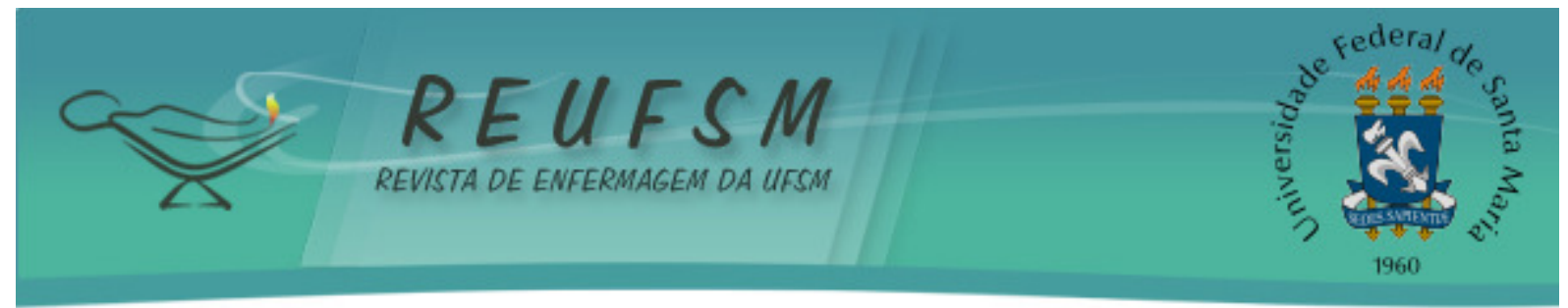

receber solicitação de exames e prescrição médica, desviando o objetivo de construção de um espaço de diálogo educativo entre a equipe de saúde e os usuários do serviço.

E se eu não posso fazer muita coisa, eu pelo menos solícito uns exames pra eles e eles fazem no laboratório e pelo menos eles vêm e saem satisfeitos. (VIOLETA)

Para eu conseguir um número maior, tenho que fazer uma brincadeira, alguma coisa que incentive e que estimule a vinda. $E$ tem que ter troca, tem que ter a receita médica, ai então a clientela vem. (LÍRIO)

A educação em saúde nos serviços necessita de mudanças efetivas no que se refere a maior atuação dos profissionais da área da saúde, para isto é necessário que ocorra uma mudança na postura destes profissionais em relação à efetivação da participação da população e aumento no acesso aos serviços de saúde, de acordo com as necessidades e demandas da comunidade. ${ }^{21}$

Para tanto, os profissionais da área da saúde, devem ampliar a habilidade de dialogar, meio essencial para o desenvolvimento de uma relação intersubjetiva, que contribua não somente para aumentar a relação entre profissional e o usuário, mas também à realização das atividades rotineiras dos serviços. ${ }^{18}$

Por outro lado, há profissionais que enfrentam as dificuldades utilizando seus princípios e valores, como pessoas e como cidadãos. Nesse caso a humanização também é uma forma de confrontar essa realidade da prática educativa na atenção primária.

Eu procuro como ferramenta usar a terapia para melhorar as minhas rodas de conversa. E pelo lado da humanização, o enfermeiro é mais humano, então isso me facilita muito, não aquela humanização mesmo preconizada pelo SUS, mas a minha enquanto cidadã, enquanto profissional responsável pela comunidade. (ORQUÍDEA)

Diante da importância de práticas dialógicas de educação em saúde, a enfermagem deve promover uma assistência que respeite o usuário como pessoa humana em sua dignidade, liberdade e autonomina, visualizando-o e garantindo seus direitos humanos básicos promovendo a humanização nos espaços onde se desenvolvem os serviços de saúde. ${ }^{22}$

\section{Facilidades no desenvolvimento das ações educativas na prática da atenção primária}

A dimensão das ações educativas no cotidiano das enfermeiras na atenção primária não se configura somente com entraves para sua realização, visto que toda atividade desenvolvida em conjunto necessita da mínima habilidade e afinidade para ser concretizada. Dessa forma, foi válido no estudo buscar quais facilidades as profissionais têm no desenvolvimento de suas ações educativas.

A gente atende junto, a médica atende junto com a enfermeira, ela atende e depois eu atendo, o que eu não posso fazer eu passo para ela, mas tudo é em conjunto. [...] A comunidade não deixa de ajudar a gente, eles sabem, eles vêm aqui, eles sabem das dificuldades, mas eles também 


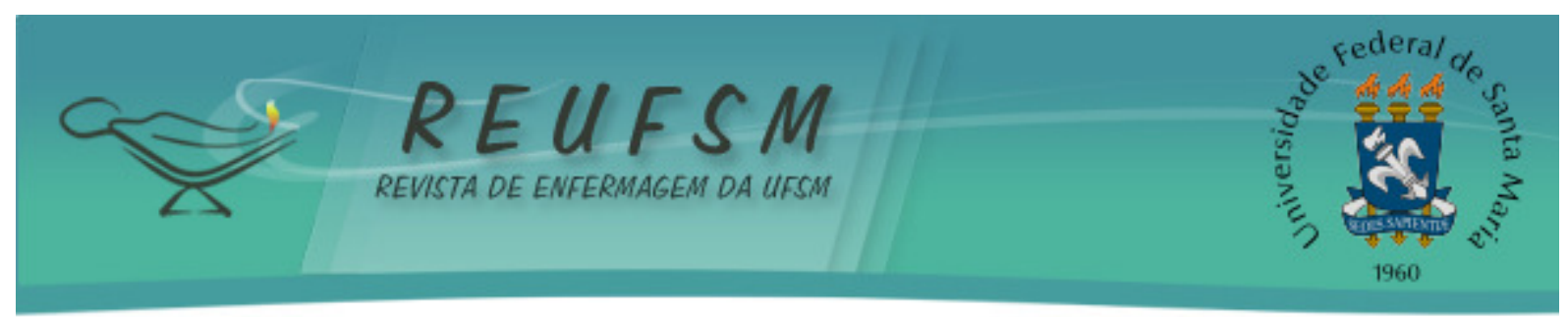

procuram ajudar. A própria equipe, os ACSs se empenham muito. (ROSA)

Foram percebidas as facilidades no desenvolvimento das ações educativas junto ao trabalho conjunto que é desenvolvido pela equipe da Unidade, bem como a parceria entre a equipe de saúde e a comunidade, que, conhecedora das dificuldades enfrentadas em seu cotidiano, colaboram de forma decisiva com o trabalho das enfermeiras.

Esse contexto reforça a importância do trabalho da equipe multiprofissional nos serviços de saúde, que busca a reorganização do processo de trabalho em saúde e a mudança na maneira de agir em relação aos fatores que comprometem o processo saúde/doença dos usuários, utilizando-se de uma maior interação entre os profissionais e as ações desenvolvidas. ${ }^{23}$

Desenvolver ações educativas dialógicas no contexto da ESF ainda é um grande desafio, mas já é um reconhecimento válido no contexto das enfermeiras participantes desta pesquisa.

A gente procura ouvir mais a comunidade, ouvir o que eles realmente querem e ai dá para a gente ter uma noção de como é que a gente vai trabalhar com a comunidade, isso me facilita. (ORQUIÍDEA)

Nessa perspectiva é fundamental acrescentar que não basta somente interação da equipe, é preciso trazer a comunidade para o contexto das atividades, é importante para a equipe multiprofissional desenvolver vínculos com os usuários, para que possam conhecer e intervir mais efetivamente na realidade em que estão inseridos.

Nesse sentido, para superação dos modelos tradicionais de educação em saúde é necessário que haja o enfretamento entre os saberes. Saberes que possuem conhecimentos técnicos e científicos frente aos acontecimentos e a maneira como se mostram as necessidades de saúde dos usuários dos serviços. ${ }^{18}$

A busca em desenvolver uma prática educativa voltada para o diálogo, procurando conhecer o cotidiano da comunidade, demonstra que a mudança no processo educativo em saúde já é uma realidade, mesmo que incipiente, nas práticas desenvolvidas na atenção primária.

\section{CONSIDERAÇÕES FINAIS}

Com o estudo foi possível conhecer a prática de educação em saúde das enfermeiras e suas dificuldades e enfrentamentos na realidade em que estão inseridas. A partir das perspectivas das profissionais quanto à dimensão das ações educativas, percebeu-se que elas avaliam positivamente o seu trabalho e que o modelo tradicional (informativo) é o norteador predominantemente adotado nas práticas educativas.

Contudo, busca-se conhecer e reconhecer as necessidades, dificuldades e carências da população. Entretanto, essa prática ainda é pouco utilizada como estratégia de educação em saúde no cotidiano das enfermeiras.

As profissionais fazem pouco uso do conhecimento científico, predominando ações voltadas apenas para o repasse de informações, o que dificulta o diálogo e a construção de alternativas para transformar a realidade e as condições de vida da população.

Os entraves como barreiras institucionais relacionadas às limitações de recursos materiais e de espaço físico, o desinteresse da população em participar das atividades e a violência da localidade, influenciam de forma negativa o pleno desenvolvimento das práticas das enfermeiras, pois limitam as ações educativas, desestimulam as profissionais na sua realização, assim como afastam a comunidade. 


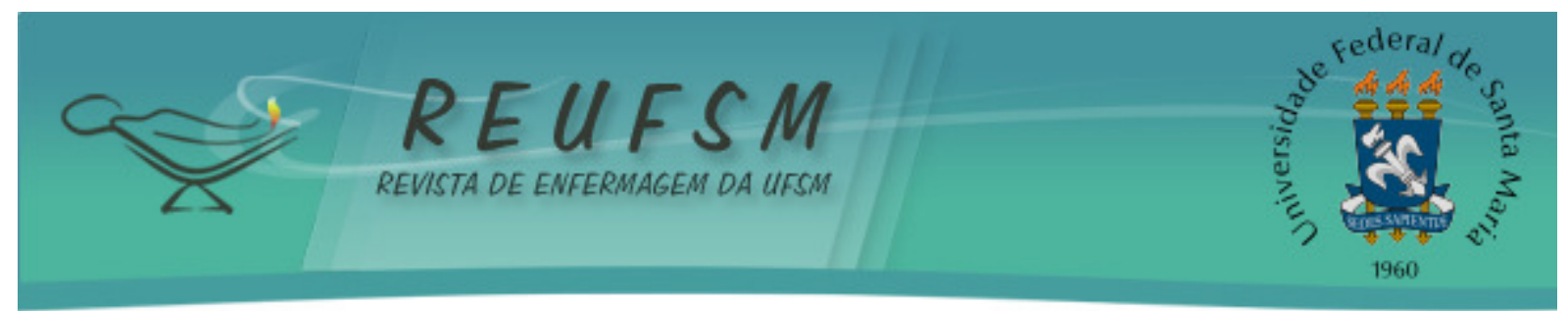

Como estratégias para enfrentar as dificuldades, as parcerias com instituições externas, a colaboração ativa dos profissionais da equipe, a compra de materiais com recursos próprios, além do desenvolvimento de dinâmicas e a oferta de outros serviços para atrair a população às ações educativas, foram destaques. No entanto, é válido ressaltar que estas não revelam o verdadeiro intuito da educação em saúde e não contribuem para mudanças na realidade da comunidade.

Mesmo assim, relatos demonstram que há preocupação em realizar um trabalho comprometido com ações cidadãs e humanizadas, viabilizando assim, o melhor desenvolvimento das ações educativas. E apesar da utilização de maneiras pouco sistemáticas de educação em saúde, há um discurso comprometido com as necessidades de saúde da população e com a construção de práticas educativas participativas, mesmo sendo uma perspectiva ainda tímida no contexto do estudo.

Diante dos resultados, entende-se que, mesmo num contexto em que as formas tradicionais insistam em se perpetuar, colocam-se novos modos de pensar a prática educativa, e que mesmo diante das dificuldades, no espaço cotidiano do serviço aqui pesquisado têm se desenvolvido possibilidades de reinvenção, compartilhamento e recriação das formas de educar em saúde.

Acredita-se que essa abordagem ainda seja um desafio para as enfermeiras atuantes na Atenção Primária, mas que deve ser pensada como um processo a ser galgado pelos profissionais dos serviços de saúde, quando no desenvolvimento de práticas educativas voltadas para a realidade da população.

\section{REFERÊNCIAS}

1. Chiesa AM, Veríssimo MDLOR. A educação em saúde na prática do PSF. In: BRASIL. Instituto para o Desenvolvimento da Saúde. Universidade de São Paulo. Manual de enfermagem. Brasília (DF): Ministério da Saúde; 2001. p.34-42. (Série A. Normas e Manuais Técnicos; $\mathrm{n}^{\circ}$ 135).

2. Machado MFAS, Monteiro EMLM, Queiroz DT, Vieira NFC, Barroso MGT. Integralidade, formação de saúde, educação em saúde e as propostas do SUS: uma revisão conceitual. Ciênc Saúde Coletiva. 2007;12(2):335-42.

3. Coelho MMF, Torres RAM, Miranda KCL, Cabral RL, Almeida LKG, Queiroz MVO. Educação em saúde com adolescentes: compartilhando vivências e reflexões. Ciênc Cuid Saúde. 2012;11(2):390-5.

4. Souza LM, Wegner W, Gorini MIPC. Educação em saúde: uma estratégia de cuidado ao cuidador leigo. Rev Latinoam Enferm. 2007;15(2):337-43.

5. Brasil. Ministério da Saúde. Secretária de Gestão Estratégica e Participativa. Departamento de Apoio à Gestão Participativa. Bases para a Educação em Saúde nos Serviços. Brasília (DF); 2008. p. 1-3.

6. Leonello VM, Oliveira MAC. Competências para ação educativa da enfermeira. Rev Latinoam Enferm. 2010;16(2):177-83.

7. Brasil. Ministério da Saúde. Secretaria de Atenção à Saúde. Departamento de Atenção Básica. Política nacional de atenção básica. Brasília (DF): Ministério da Saúde; 2006. (Série Pactos pela saúde 2006; v.4).

8. Brasil. Conselho Nacional de Secretários de Saúde. Atenção Primária e Promoção da Saúde. Brasília (DF): CONASS; 2011. 


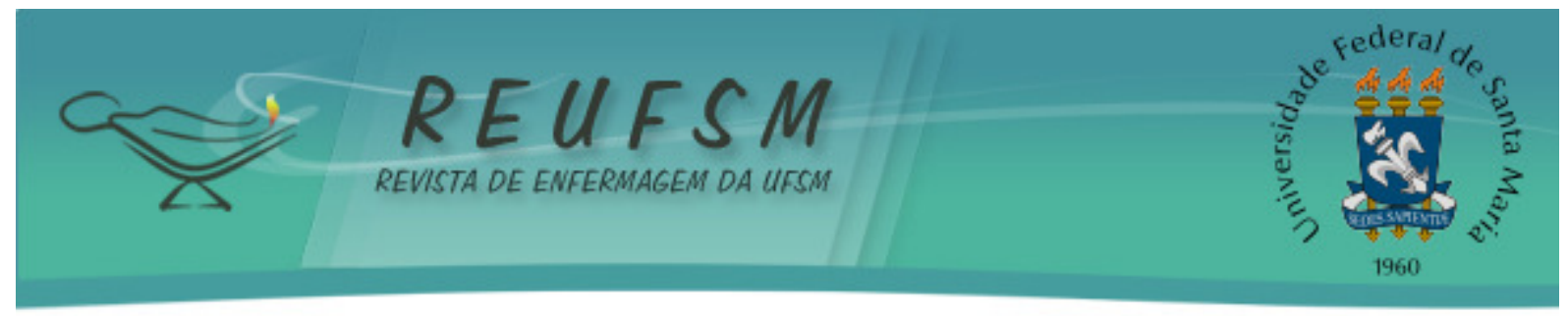

9. Strauss AL, Corbin JM. Pesquisa qualitativa: técnicas e procedimentos para o desenvolvimento de teoria fundamentada. $2^{\mathrm{a}}$ ed. Porto Alegre (RS): Artmed; 2008.

10. Figueiredo NMA. Práticas de enfermagem: ensinando a cuidar em saúde pública. $1^{a}$ ed. São Caetano do Sul (SP): Yendis Editora; 2005.

11. Silva LD, Beck CLC, Dissen CM, Tavares JP, Budó MLD, Silva HS. O enfermeiro e a educação em saúde: um estudo bibliográfico. Rev Enferm UFSM [Internet]. 2012 [acesso 2013 jan 18];2(2):412-9. Disponível em: http://cascavel.ufsm.br/revistas/ojs2.2.2/index. php/reufsm/article/view/2676.

12. Acioli S. A prática educativa como expressão do cuidado em Saúde Pública. Rev Bras Enferm. 2008;61(1):117-21.

13. Roecker S, Silva MS. Educação em saúde. Relatos das vivências de enfermeiros com a Estratégia da Saúde Familiar. Invest Educ Enferm. 2011;29(3):381-90.

14. Alves VS. A health education model for the Family Health Program: towards comprehensive health care and model reorientation. Interface Comunic Saúde Educ. 2005;16(9):39-52.

15. Stotz EM, Araújo JWG. Promoção da saúde e cultura política: a reconstrução do consenso. Saúde Soc. 2004;13(2):5-19.

16. Malta DC, Merhy EE. The path of the line of care from the perspective of nontransmissible chronic diseases. Interface Comunic Saúde Educ. 2010;14(34):593-606.

17. Hammerschmidt KSA, Zagonel IPS, Lenardt MH. Envolvimentos da teoria do cuidado cultural na sustentabilidade do cuidado gerontológico. Acta Paul Enferm. 2007;20(3):362-7.

18. Dantas MBP. Educação em saúde na atenção básica: sujeito, diálogo, intersubjetividade [tese]. Recife: Centro de Pesquisas Aggeu Magalhães, Fundação Oswaldo Cruz; 2010. 234 p.

19. Pereira APCM, Servo MLS. A enfermeira e a educação em saúde: estudo de uma realidade local. Rev Baiana Saúde Pública. 2006;30(1):7-18.

20. Lopes MMB. Educação em enfermagem na UFPA e a práxis da enfermeira na atenção básica de saúde [tese]. Florianópolis: Universidade Federal de Santa Catarina, Programa de Pós-Graduação em Enfermagem; 2009. 270 p.

21. Bornstein VJ, Stotz EN. O trabalho dos agentes comunitários de saúde: entre a mediação convencedora e a transformadora. Trab Educ Saúde. 2008;6(3):457-80.

22. Shiratori K, Costa TL, Formozo GA, Silva SA. Educação em saúde como estratégia para garantir a dignidade da pessoa humana. Rev Bras Enferm. 2004;57(5):617-19.

23. Costa RKS, Enders BC, Menezes RMP. Trabalho em equipe de saúde: uma análise contextual. Ciênc Cuid Saúde. 2008;7(4):530-6.

Data de recebimento: $11 / 02 / 2013$

Data de aceite: $20 / 11 / 2013$

Contato com autor responsável: Geyse Aline Rodrigues Dias

Endereço postal: Rodovia Arthur Bernardes; Passagem Santa Cruz n 04; Bairro: Telegrafo; Belém, PA, Brasil; CEP: 66115-080

E-mail: geysealine@hotmail.com 